\title{
O TRABALHO INVISÍVEL NO SERTÃO E O SABER-FAZER DAS MULHERES NA PRODUÇÃO DE QUEIJO
}

\author{
Luci Mara Bertoni ${ }^{1}$ \\ Sônia de Souza Mendonça Menezes
}

\section{RESUMO}

Nos municípios de Nossa Senhora da Glória, Porto da Folha e Monte Alegre de Sergipe localizados no território do Alto Sertão Sergipano, identificamos a produção de Queijo de Coalho Caseiro, considerada como uma residual forma de aproveitamento do leite diante do avanço da "modernização". Neste artigo, temos por objetivo investigar em que medida o sistema de produção do queijo de coalho caseiro no espaço rural está alicerçado na transmissão do saber-fazer e na identidade das sertanejas propiciando a manutenção de um modo de vida no espaço rural. A nossa reflexão se apoia numa pesquisa fundamentada nas redes sociais nas quais as produtoras são identificadas a partir da indicação da comunidade nos citados municípios. Após visitar os espaços de produção, realizamos observação participante de suas práticas, evidenciamos essa troca de saberes com as novas gerações como um processo de educação profissional das mulheres na parte interna das residências. Além disso, constatamos o nível de educação formal dessas mulheres e as articulações informais organizadas para aproveitar os recursos territoriais. Investigamos em que medida esse trabalho considerado invisível está integrado em redes informais, alimentado pela demanda de um mercado consumidor que busca, no consumo desse alimento, uma aproximação ao território de origem. A renda obtida com a comercialização do produto constitui no principal recurso utilizado para a obtenção de alimentos nas feiras semanais contribuindo para a soberania alimentar o grupo familiar e o suíno, criado com o resíduo da produção, é uma poupança sob domínio feminino.

Palavras-chave: Saber-fazer; Educação; Mulheres; Queijo coalho.

\section{THE INVISIBLE WORK IN THE BACKLANDS AND WOMEN EXPERTISE WHEN PRODUCING CHEESE}

\section{ABSTRACT}

A homemade production of curd cheese was found in the small cities of Nossa Senhora da Glória, Porto da Folha and Monte Alegre de Sergipe. These cities are located on the High Backlands from Sergipe and their cheese production is considered a residual way of reuse the milk in the face of "modernization" advances. This article aims to investigate to what extend the curd cheese's production system in the countryside is based on knowledge transmission and country people identity, and how it makes the maintenance of a country life style possible. Our thoughts rely on a social network based research, in which the producers are identified by the citizens' indications. After visiting the production areas, we performed a participating observation, and it was possible to witness the knowledge exchange with the new generation as a home educational process. Besides, we verified the women formal education and the informal articulations organized to reuse territorial resources. We investigated to what extend this invisible job is joint to informal networks, 
supplied by consumers that look for reconnect with their original territory when consuming this food. Marketing this product is these people main income, and it is used to buy food at the weekly fairs, which contributes to the family and swine's food sovereignty. The animals are fed with the rest of the production and it is a women controlled way to save money.

Keywords: Knowledge; Education; Women; Curd cheese.

Algumas questões atuais vêm sendo debatidas no intuito de trazer à luz pessoas e fazeres que merecem o devido respeito e importância. Neste sentido, compreendemos que, na sociedade brasileira, constituída de grande diversidade, alguns lugares se tornaram pouco conhecidos. De maneira geral, os(as) estudiosos(as) de gênero há tempos vêm chamando a atenção para o trabalho da mulher (particularmente, o doméstico) que por acontecer no espaço privado, não tem valor e visibilidade. O que nos inquieta, neste momento, é o fato de que muitas mulheres, além do exaustivo trabalho doméstico, são responsáveis pela garantia da manutenção e do sustento de seus lares (ainda que tenham companheiros).

Em se tratando do trabalho da mulher nos centros mais conhecidos temos ainda muito que saber sobre essas atoras ${ }^{3}$, quanto mais quando adentramos os espaços rurais dos Estados e nos deparamos com mulheres anônimas que fazem da história de suas vidas, a história desses locais. Assim, nos interessa apresentar aqui a relação de trabalho das mulheres queijeiras do sertão sergipano e o seu saber fazer que é passado de geração em geração como formas de educação e manutenção de sua cultura e de sua própria existência e da sobrevivência de sua família no espaço rural.

\section{O Sertão sergipano como locus do trabalho das mulheres}

No Sertão sergipano, as atividades agrícolas estão enraizadas desde o período de ocupação do território e a pecuária desponta como a principal prática asseguradora de recursos para os sertanejos e proporcionadora de alimentos arraigados na dieta como o leite, o queijo de coalho e a carne bovina, além de propiciar os animais para as festas típicas como as vaquejadas e a corrida de mourão.

A história da ocupação dessa região, no século XVI, deu-se com a doação de grandes e pequenas glebas de terras pela Coroa Portuguesa, visando firmar a posse, então ameaçada pelas invasões holandesas. Nesse bojo, os indígenas foram empurrados para outras terras, processo violento e perverso no qual tribos inteiras foram dizimadas.

Nos séculos XVII e em parte do século XVIII, a região não correspondia às fronteiras econômicas definidas pelo Estado. Embora tenham participado outras categorias populacionais no povoamento, o Sertão tem no vaqueiro um dos agentes precursores da ocupação: "utilizando-se da quarteação, acabou por se transformar em criador, dando origem a uma estrutura de pequenos pecuaristas que persiste até os dias atuais" (DINIZ, 1996, p.52). Os animais se aclimataram ao ar seco e saudável e alimentavam-se das gramíneas naturais existentes. A forragem encontrada no meio da caatinga não proporcionava alto potencial nutritivo, mas propiciava a subsistência dos rebanhos rústicos e resistentes, adaptados às dificuldades no tocante à alimentação e água, tais condições resultavam em uma reduzida taxa de ocupação de animais por hectare. No período do inverno, com a chegada das chuvas, os vaqueiros juntavam os animais e traziam para as sedes dos estabelecimentos rurais.

Além da criação de gado, os camponeses no Sertão dedicavam-se aos cultivos de milho, feijão, mandioca e algodão, abastecendo as grandes propriedades e a população urbana que crescia. No entanto, a produção de alimentos não se constituiu na atividade mais 
importante do Sertão, como destaca Andrade (1986), esta desenvolveu mediocremente à sombra dos "currais". Sendo assim, na história do Sertão nordestino, a produção do queijo de coalho passa a ser considerada como um legado dos camponeses fundamental na alimentação diária, ressaltada nas pesquisas de Castro ([1963] 2011), Cascudo (2004), Andrade (1988) e em obras literárias como "O Sertanejo" (ALENCAR, 1969). O queijo começa a fazer parte da cultura alimentar e está presente nas refeições diárias e nos deslocamentos da população que o consumia juntamente com a farinha e/ou outros alimentos.

Entretanto, nas décadas de 1960 e 70, no Estado de Sergipe, ocorreu a difusão do paradigma da revolução verde ${ }^{4}$ com o incentivo da mecanização do campo que proporcionou o incremento do êxodo rural. Aliada à modernização da agricultura, ocorreu nesse período, a expansão do setor de transportes e o crescimento do setor industrial que aceleraram igualmente o movimento migratório que provocou o deslocamento de parte integrante dos trabalhadores/trabalhadoras inserida na cadeia produtiva agrícola. Essas mudanças provocadas no modo de vida de muitos sertanejo(a)s implicaram em várias alterações, principalmente, aquelas relacionadas ao novo habitat. Entretanto, no novo habitat os migrantes buscam conservar o consumo de alimentos enraizados como o queijo de coalho. Logo, esse alimento passa a ser demandado pelos migrantes no meio urbano após a perda da autonomia na produção uma vez que, na cidade, eles não possuíam terra disponível para plantar, criar animais e produzir alimentos como o queijo.

Nos últimos anos, as pesquisas mostraram que a alimentação constitui um dos traços identitários enraizados e sua preservação é buscada, incessantemente, pelos migrantes deslocados ou descolados do seu território. Eles tentam, com o consumo de determinados produtos, uma aproximação do seu território. Ao alimentar o corpo alimentam também a alma (MENEZES, 2009). O registro familiar dessa comida é memória de aromas e gostos da infância, através de gerações o saber-fazer ${ }^{5}$ é acumulado e transmitido por diferentes gerações (MENEZES, 2015). Conforme Mintz (2001), os alimentos estão associados com o passado de quem os consome, as técnicas utilizadas para elaborar, servir e consumir os alimentos são variadas, indicadoras de suas próprias histórias. Nessas histórias estão presentes os valores culturais, as representações em torno das práticas de obtenção, preparação e consumo de alimentos, os quais auxiliam na construção e na manutenção de identidade dos grupos sociais. Ao mesmo tempo, que o saber fazer é passado entre gerações, outros valores educativos são transmitidos na mesma proporção.

Partimos das premissas de que as questões relacionadas à educação para o trabalho perpassam as relações da educação de gênero (GALINKIN E BERTONI, 2014) fortemente fortalecidas no âmbito familiar. Neste espaço, dá-se a primeira forma de educação e de socialização de gênero quando começamos a aprender os diferentes papéis e as diferentes tarefas estabelecidas para meninos e meninas. O que será incrementado na educação escolar quando esta formação vai direcionar diferentes profissões destinadas a homens e mulheres. Nas relações sociais, a categoria gênero será sempre demarcada, o que não será distinto nas diversas comunidades.

Neste artigo, temos como objetivo investigar em que medida o sistema de produção do queijo de coalho caseiro no espaço rural está alicerçado pela transmissão do saber-fazer e na identidade das sertanejas propiciando a manutenção de um modo de vida no espaço rural. Nesse sentido comungamos com as análises formuladas por Saviani (2007, p.154) ao abordar a conexão entre trabalho e educação como uma relação de identidade. Em suas palavras: 
Os homens aprendiam a produzir sua existência no próprio ato de produzila. Eles aprendiam a trabalhar trabalhando. Lidando com a natureza, relacionando-se uns com os outros, os homens educavam-se e educavam as novas gerações. A produção da existência implica o desenvolvimento de formas e conteúdos cuja validade é estabelecida pela experiência, o que configura um verdadeiro processo de aprendizagem.

Embora Saviani (2007) não tenha estudado a produção de queijos no espaço rural sergipano, evidenciamos que essa discussão assemelha-se à aprendizagem da elaboração do queijo, uma vez que a experiência, os saberes são transmitidos pelas mulheres no ato de produzir, como elas ressaltam "o queijo se aprende fazendo", o que evidencia a imbricação do trabalho com o processo educativo.

Assim, após uma breve apresentação da temática e da metodologia adotada, abordaremos a produção de queijos, as articulações dos produtores e comerciantes, a organização dos fluxos, as redes criadas com o objetivo de escoar a produção e obter a renda essencial na sustentabilidade do estabelecimento familiar.

\section{Queijo de coalho caseiro}

Os municípios de Nossa Senhora da Glória, Porto da Folha e Monte Alegre de Sergipe estão localizados no Alto Sertão Sergipano apresentando as mesmas características edafoclimáticas e a pecuária leiteira constitui na principal atividade econômica.

\section{Localização dos Municípios de Porto da Folha, Monte Alegre de Sergipe e Nossa Senhora da Glória - SE.}
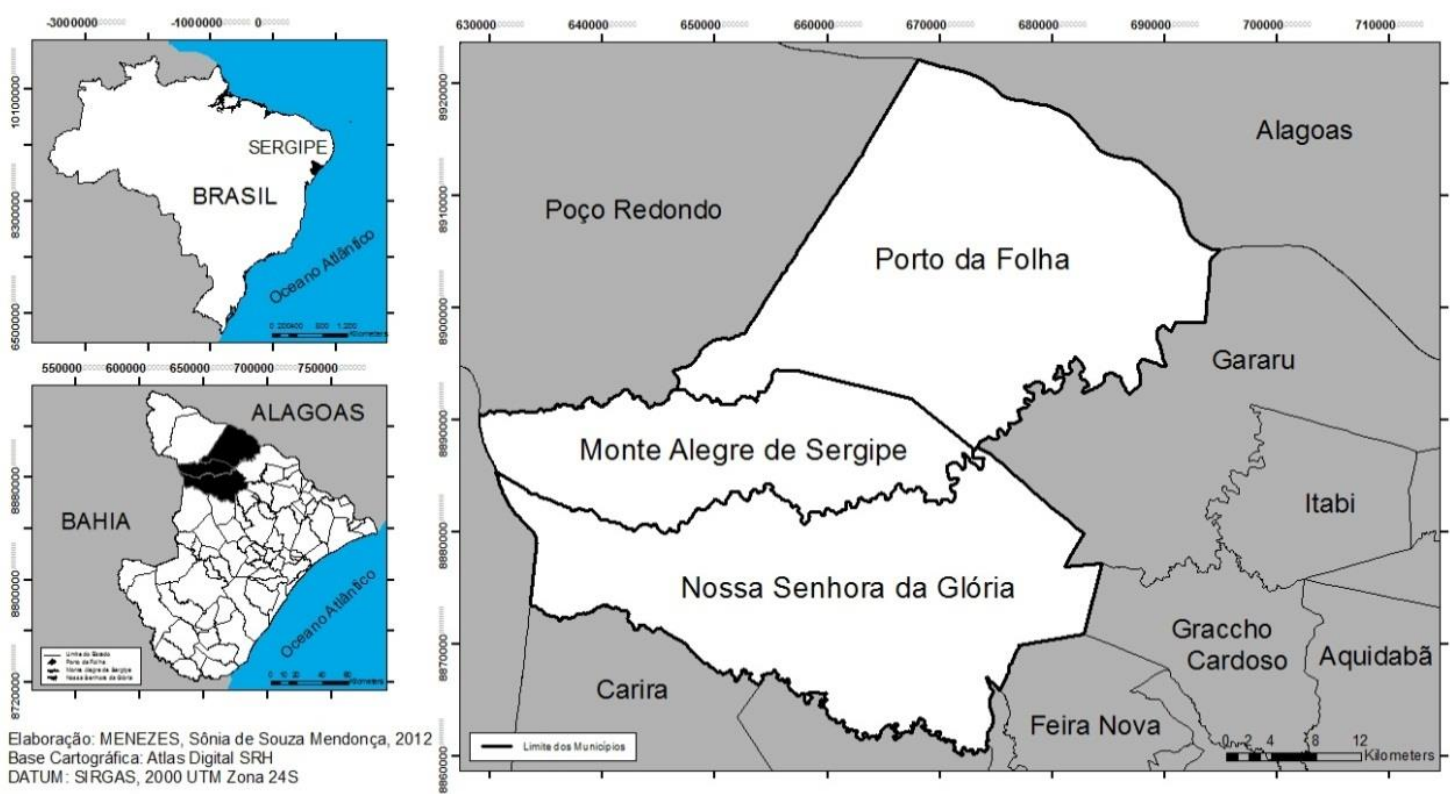

Figura 01: Localização geográfica dos municípios de Nossa Senhora da Glória, Porto da Folha e Monte Alegre de Sergipe.

Nos citados municípios predomina o clima semiárido, incluindo-se no polígono das secas, onde segundo Conti e Furlan (2008), as médias térmicas ultrapassam os $26^{\circ} \mathrm{C}$ e as médias pluviométricas variam de $365 \mathrm{~mm}$ a $630 \mathrm{~mm}$ anuais. Outra característica do clima semiárido é a elevada evaporação que implica a deficiência hídrica, especialmente no 
período de primavera-verão, podendo de igual modo se prolongar por todo o ano, volumes insuficientes para o desenvolvimento convencional da agricultura e da pecuária.

A criação de gado bovino que ocorre desde o processo de ocupação dos municípios permitiu o surgimento de vilas e cidades. Inicialmente, predominava a criação do gado de corte, com raças rústicas (gado pé duro) resistentes ao clima e adaptadas à vegetação da caatinga. Nesse interim, a produção de leite obtida era reduzida tendo em vista que os animais eram destinados à produção de carne. Esses animais produziam cerca de cinco a seis litros de leite/dia nos períodos chuvosos quando alimentavam-se da vegetação rasteira e de gramíneas. No verão, com as dificuldades relacionadas à alimentação dos animais, o leite produzido destinava-se exclusivamente à alimentação da família e, nos períodos de seca, as vacas cessavam a produção de leite. Logo, o queijo de coalho era produzido nos períodos chuvosos, tempo de fartura, objeto de troca para alguns e, sobretudo, alimento típico comum nos momentos das refeições.

Na década de 1970, a pecuária em Sergipe, localizada principalmente no Agreste e Sertão, tem seu crescimento acelerado. Esse crescimento fora consequência de alguns fatores favoráveis como: melhores estradas, clima propício às pastagens, menor incidência de doenças no rebanho bovino nessa região e uma política de crédito agrícola voltada, principalmente, para o semiárido por meio dos Projetos PROTERRA, POLONORDESTE e SERTANEJO. Tais projetos incentivaram a atividade pecuarista com linhas de créditos direcionadas à aquisição de animais com um padrão genético propício à produção de leite ou aqueles especializados para a produção de carne, o que proporcionou a mestiçagem do rebanho. Além disso, foram introduzidas pastagens plantadas, com a inserção de vários tipos como: buffel (Cenchrus ciliaris), pangola (Digitaria decumbens $S$ ) e a braquiária (Brachiaria decumbens) (MENEZES, 2009).

Em meio ao avanço dos setores terciário e secundário, observou-se o declínio do poder do setor primário e, no tocante ao agricultor familiar, ocorre a derrocada do cultivo do algodão nesse Estado, devido à praga do bicudo - Anthono-musgandis - que teve reflexos na perda de valor comercial do produto. Nesse contexto, contraditoriamente, verificou-se o crescimento da pecuária, nos estabelecimentos pertencentes aos agricultores familiares do Sertão Sergipano, alicerçados pelo leite, produto com inserção no mercado.

O pequeno estabelecimento rural (com até 50 ha), ocupado anteriormente com a lavoura de milho, feijão, mandioca e algodão, consorciados, transformou-se com a inserção das pastagens direcionadas para o gado leiteiro. A permuta do cultivo agrícola pela pastagem decorreu do rendimento mais estável e seguro da pecuária e viabilizava a persistência familiar, criando, dessa forma, uma estratégia de reprodução social.

Woortmann (1995), ao estudar municípios sertanejos em Sergipe, faz uma análise comparativa da criação de gado. Enquanto, no grande estabelecimento, a pecuária tem como principal objetivo o lucro, no pequeno estabelecimento no Sertão e nos sítios do Agreste sergipano, o significado é outro como expressa a autora:

No sítio o gado é "criação" e corresponde a uma atividade meio. Seu significado é basicamente o de uma reserva de valor; garantia contra os efeitos da seca, à qual ele resiste mais que a lavoura; o de uma forma de acumulação ou de poupança, destinada à aquisição de terra, inclusive para possibilitar a herança. (WOORTMANN, 1995, p. 286).

Esta assertiva procede e reflete a realidade vivida pelos camponeses sertanejos igualmente na atualidade. Nos relatos das mulheres entrevistadas ${ }^{6}$ é contundente a importância da transformação do uso da terra que viabiliza a sua continuidade no território e a independência diante outras atividades com sujeição ao patronato. Muito embora a 
criação de bovinos constitua o principal objetivo dos agricultores, ainda observaram-se criações de outros animais, com elevado valor simbólico nos pequenos estabelecimentos. Assim, identificamos a criação de aves como galinhas, perus e guinés, além das miunças (ovelhas, carneiros, bodes e cabras), considerados animais de médio porte, nos pequenos estabelecimentos, sob a responsabilidade das crianças e das mulheres. Tais criatórios fazem parte do que a Woortmann (1995, p. 287) denomina de "ciclo evolutivo da criação". Tendo em vista que o objetivo da criação desses animais é adquirir renda para utilizar na aquisição de bovinos e posteriormente comercializá-los para conseguir comprar os denominados pedaços de terras. Em casos excepcionais, a família poderá utilizar ou apropriar-se dos bens e recursos financeiros do(a) filho(a) tendo, porém, o compromisso moral de ressarci-lo(a), posteriormente.

Assim, a criação do gado bovino, nesses estabelecimentos, está restritamente relacionada ao sexo masculino e os espaços do seu domínio. O pasto constitui um território sob o seu comando e, conforme Woortmann (1995, p.286), indica "a capacidade do pai de família de criar ou manter um patrimônio". Enquanto isso, as cercanias da residência, o quintal, é o território feminino onde as mulheres organizam seus criatórios, pequenos cultivos com ervas medicinais, pequenas roças de milho, feijão, as frutas típicas do sertão e as aves o que a "revelam uma dona de casa caprichosa". Geralmente, no entorno das residências, são inseridas inúmeras plantas ornamentais que embelezam o mundo rural.

A divisão sexual do trabalho nos municípios sertanejos sempre foi definida pelo homem, cabendo à mulher a tarefa de transformar os produtos do roçado ou os mantimentos em alimentos comestíveis. Woortmann \&. Woortmann (1997, p. 37) afirmam que, contrapondo a posição masculina, a mulher ocupa um lugar determinado: "a casa, núcleo simbólico da família". Nessa direção, Claval (1999, p. 85) afirma que "a carga afetiva da casa é forte. Ela aparece como um território onde a presença feminina é particularmente forte. Ao homem cabe controlar os espaços produtivos externos a casa, cabe à mulher o governo da mesma".

Essa assertiva encontra respaldo também na leitura da dominação masculina discutida por Bourdieu (1999, p. 18), que assevera: "a estrutura do espaço opondo o lugar da assembleia ou de mercados, reservados aos homens, e a casa, reservada às mulheres". Ao subtrair do sexo feminino, o valor do seu trabalho de forma quase exclusiva, restando os espaços do lar ou suas cercanias, a atividade feminina é considerada, geralmente, como ajuda, por estar vinculada às tarefas domésticas pouco valorizadas. Nessa direção, Hirata e Kergoat (2007, p. 599) asseveram que "a divisão sexual do trabalho é a forma de divisão do trabalho social decorrente das relações sociais entre os sexos [...]". Ainda, de acordo com as autoras:

Essa forma particular da divisão social do trabalho tem dois princípios organizadores: o princípio de separação (existem trabalhos de homens e trabalhos de mulheres) e o princípio hierárquico (um trabalho de homem "vale" mais que um trabalho de mulher). (HIRATA e KERGOAT, 2007, p. 599).

As ideias desenvolvidas pelas autoras supracitadas não se chocam, mas, ao contrário, complementam-se e enriquecem-se mutuamente. Embora em alguns períodos do ano como nas estações do ano como a primavera, verão e outono o queijo seja a principal renda familiar as mulheres não vislumbram a relevância do teu trabalho como fundamental na reprodução social da família.

As mulheres sertanejas, com as raras exceções, sempre estiveram reclusas ao lar, expandindo o seu domínio em alguns períodos no campo, sobretudo até a década de 1970 e 80. Responsáveis pela alimentação da família, até a década de 70, elas aproveitavam das 
potencialidades existentes no meio para elaborar iguarias, em virtude da (quase) inexistência de produtos industrializados no meio rural. Nesse contexto, os alimentos consumidos eram praticamente produzidos no interior do estabelecimento rural e as dietas das comunidades estavam relacionadas aos alimentos da terra.

A dieta sertaneja fundamentada nos derivados do milho e do leite perdurou inalterada até a década de 1990. Pela manhã, enquanto o homem ordenhava as vacas, as mulheres ralavam o milho seco e, em seguida, elaboravam o cuscuz e o café. Após o ordenhamento das vacas, o leite era levado para a residência pelas crianças (de acordo com o volume) ou por um adulto e entregue à mulher. Ela separava parte do leite que seria consumido da outra parte utilizada para a elaboração do queijo de coalho e da coalhada, ingrediente essencial na dieta dos sertanejos no café da manhã ou nos momentos de merenda e sobremesa. A nata retirada da coalhada era utilizada para a elaboração de manteiga em creme e da manteiga de garrafa. Juntamente com esses alimentos serviam ainda ovos obtidos da criação e, nas famílias com maior poder aquisitivo, a carne do sol ou o charque. Tradição que, de alguma maneira, ainda sobrevive em algumas comunidades e famílias.

\section{A produção do queijo de coalho caseiro: a resistência da tradição e transmissão do saber-fazer}

Nos estabelecimentos dos agricultores familiares, a ordenha das vacas é realizada manualmente a partir das cinco horas da manhã, predominantemente pelos homens, nos currais localizados nas proximidades das residências. Identificamos somente duas produtoras em Monte Alegre e Porto da Folha, respectivamente, que realizavam a referida atividade. Após o término da citada atividade, o leite é coado e levado para as residências. Desse modo, na produção queijeira, o leite, que é o produto do trabalho do homem "retorna para casa, onde passa para o governo da mulher" (Woortmann, 1997, p.38) e se torna o principal recurso da elaboração do queijo caseiro, tornando-se produto do trabalho feminino.

As mulheres separam uma parte do leite para o autoconsumo (alimento diário nas refeições matinal e noturna) e a outra parte do leite destina-se à produção do queijo de coalho, logo é adicionado o coalho nos recipientes plásticos, deixa-se em descanso por um período de trinta minutos (esse tempo pode variar em determinadas localidades). Em tempos anteriores, o leite era coalhado com coalho obtido do estômago do animal. Em 2015, identificamos cerca de seis produtoras que ainda permaneciam elaborando o queijo com o coalho obtido naturalmente. Essas produtoras que continuavam a elaborar o coalho artesanal alegam as razões da continuidade do uso desse produto. "O queijo do coalho de boi é mais gostoso e já que é natural, eu sei de onde vem, sei o que é que tem nele é mais saudável, enquanto o químico tem muita droga e ninguém sabe de onde vem" (EBS) ${ }^{7}$.

Observamos, nos municípios citados nesta pesquisa, a predominância do uso do coalho industrializado. $\mathrm{O}$ grupo de produtoras que utilizam esse tipo de coalho argumenta que as razões para a mudança estão na praticidade do produto, na rapidez da transformação do leite em coalhada e na relação com a cor do queijo, uma vez que o coalho artesanal deixa o derivado amarelado, fato esse essencial tendo em vista que os consumidores demandam o produto branco, diferentemente do produto comercializado até a década de 1970.

No passado, as sertanejas após a enformagem do queijo, o derivado era colocado sobre uma tábua em áreas elevadas e ficava por dias maturando ou curando até ser consumido ou comercializado. Como reflexo do clima semiárido, com altas temperaturas durante todo o ano, a maturação era atingida entre 15 a 25 dias. Como ressaltam as produtoras "o queijo ficava amarelinho e escorria a manteiga dele". Quanto ao teor de sal, 
esse queijo recebia uma maior quantidade em decorrência da demanda dos consumidores e da não existência de sistema de refrigeração.

Esses produtos processados pelas mãos femininas não recebiam nenhuma ajuda masculina, uma vez que a quantidade de leite utilizada era pequena, e a cozinha não "consistia em lugar de homem". As filhas, noras, sobrinhas aprendiam a fazer o queijo olhando ou ajudando na produção dos derivados.

Até a década de 1970, alguns camponeses elaboravam o queijo diariamente e guardavam durante uma semana ou quinze dias, e levavam em caixotes de madeira no lombo dos burros para comercializar nas feiras como a de Nossa Senhora da Glória e Porto da Folha, fato semelhante ao sistema de produção dos queijos artesanais pesquisados por Meneses (2006) relativo ao Estado de Minas Gerais, e Kroner (2009) e Cruz (2012) no tocante ao queijo Serrano no Rio Grande do Sul. Ainda sobre a produção artesanal do queijo de coalho uma camponesa relembra:

Quando era criança minha mãe fazia o queijo, colocava na tábua e aos sábados arrumava em um caixote de madeira e meu pai levava para vender na feira de Glória, isso lá pros idos dos anos 60 [1960]. Com o dinheiro do queijo ele comprava café, açúcar, sal e outras coisas que a gente precisava. Nesse tempo o queijo valia pouco, porque todo mundo tinha o seu queijinho. Nós, eu e minhas irmãs ajudava a minha mãe para fazer o queijo e com as coisas de casa e no cuidado com os porcos. (M LD).

A tradição do saber-fazer do queijo de coalho caseiro nos municípios foi comprovada com as entrevistadas, ao afirmarem a transmissão desse conhecimento pelas mães, avós, sogras e tias. Além disso, verificamos a permanência da prática por outros parentes, quando $80 \%$ das entrevistadas mencionam ter alguma irmã, tia, sobrinha, que de tal modo produzem o queijo. Igualmente às discussões apresentadas por Alves (2009, p.223), "a qualificação para o trabalho [...] passa pela memória da infância e dos antepassados; o aprendizado foi sendo formado no envolvimento diário com a labuta no campo, tendo a feitura do queijo um grande significado nesse processo". Nessa direção, a sertaneja JCS, ao ser instigada como aprendeu a fazer o queijo de coalho, revela: "aprendi a fazer queijo a mais de 30 anos olhando minha mãe fazer". Sendo assim, conforme Claval (1999), a família é essencial, no que se refere ao ato de ensinar e conduzir suas experiências. $\mathrm{O}$ ato de transmitir esse aprendizado não se restringe somente ao passado, tendo em vista que, na atualidade, comprovamos a continuidade e transmissão do saber-fazer.

A difusão do saber-fazer foi comprovada em vários depoimentos. As produtoras ACD e MID ressaltaram que suas filhas, quando crianças, ficavam ao seu lado observando a organização da produção. Elas solicitavam as suas mães um pouco de massa, ou melhor, um pouco da coalhada para elaborar o seu queijinho. Assim relataram:

Minhas filhas ficavam olhando e pediam para ajudar a fazer queijo. Nós falávamos não está no tempo pois elas tinham cerca de seis anos. Depois percebi que as meninas pegavam caixa de fósforo vazia (aquelas de madeira) e faziam o seu queijinho. Elas (as crianças) diziam esse queijo é para brincar com as bonecas. Assim elas aprenderam a fazer queijo e, hoje também fazem os seus queijos.

Ainda a produtora $\mathrm{AD}$ ressaltou que sua mãe incentivava que as netas fizessem o queijo de coalho, "uma tradição familiar". Para tanto, presenteava com formas de madeira de tamanho pequeno para que as netas elaborassem o queijinho. Aos sábados, as crianças 
levavam o queijinho para a avó que fazia o pagamento e as crianças "tinha um dinheiro para comprar as retrancas [guloseimas, iguarias, doces] na feira". As meninas recebem esse estímulo para iniciar as atividades de "uma futura dona de casa sertaneja", elaborando o queijo e criando aves, atividades realizadas no território da casa ou nas suas cercanias. Recordamos que, de igual modo aos incentivos recebidos direcionados à criação de gado ao sexo masculino, as sertanejas são estimuladas a produzirem o queijo de coalho, tal fato indica a inserção da criança no sistema de produção com o objetivo da inclusão do sexo feminino ao universo de trabalho com o qual teria uma renda.

$\mathrm{Na}$ atualidade, as jovens continuam a apreender esse ofício, mas, dividem o tempo com as atividades estudantis. Embora, tenham cursado o ensino fundamental e médio em alguns casos, continuam a elaborar queijos juntamente com as suas mães, tendo em vista as dificuldades de inserção no mercado de trabalho. Utilizam dez litros de leite para a produção de um quilo de queijo. Na sua elaboração, as produtoras enfatizam o cuidado, o zelo que elas têm, não podendo descuidar das tarefas e com o tempo de execução da adição do coalho no leite, do corte da coalhada, da separação do resíduo (soro) e da enformagem realizada de maneira artesanal. Usam recipientes de plásticos denominados de bombonas para coalhar o leite, formas de madeira adquiridas no mercado local e elaboradas com madeira específica para tal fim como a imburana.

A prensagem é feita predominantemente de forma manual, mas encontramos ainda algumas produtoras que utilizam fragmentos de rochas graníticas sobre uma tábua de madeira para ajudar na dessoragem; outras se utilizam de prensas criadas em pequenas oficinas locais. Após a enformagem, o queijo é virado por várias vezes, alterando o número entre os produtores. E, no dia subsequente, esse produto é depositado em caixas plásticas, cobertas com um tecido branco. Diariamente, os queijos são retirados desses recipientes, lavados e, em determinadas comunidades, é inserida nova camada de sal. Geralmente, após três, quatro ou cinco dias, os comerciantes visitam os estabelecimentos rurais e adquirem o produto.
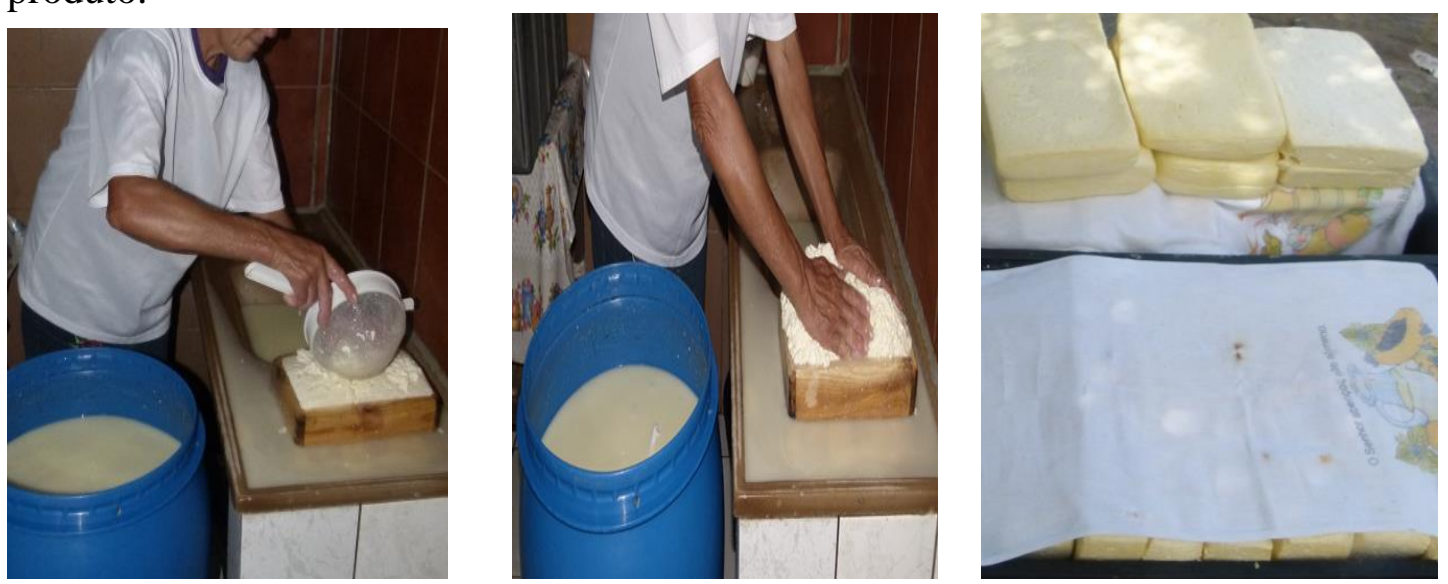

Figuras 01,02,03: Enformagem do queijo, prensagem manual e acondicionamento dos derivados nas caixas plásticas.

Mas, diante da emergência e expansão do setor formal - inserção de lacticínios indagamos se não seria mais viável para elas (mulheres), entregar o leite às indústrias e receber o pagamento semanalmente, quinzenalmente ou mensalmente, de tal modo reduziria o trabalho das mulheres. Elas alegaram valores como a tradição e a cultura. Todas elas são enfáticas ao afirmar que aprenderam com os antepassados o modo de fazer queijo, e, que não sabem fazer algo diferente, esse é o trabalho delas apreendido com as ancestrais e continuam a transmitir. Além disso, gostam dessa atividade, faz parte do modo de vida das 
sertanejas, desde criança aprenderam e continuam a produzir, lembram ainda os incentivos recebidos dos parentes. Ainda ressaltam que,

nas casas onde se faz o queijo de coalho tem uma grandeza, porque tem o leite, o queijo, o soro que pode fazer uma manteiga de garrafa e cria o porco e outros animais. Com a venda do queijo podemos comprar outros alimentos e no tempo de seca compramos a ração do gado. Essa é a nossa vida do sertão, conheci a minha avó fazendo queijo, minha mãe, eu faço, a minha filha e nora também fazem. (MLD).

Identificamos três produtoras que ressaltaram a importância do queijo para a sua família, ao mesmo tempo em que afirmaram que, nos períodos de estiagem, não podem comer ou repartir com filhos, pois precisam comercializar o queijo e, com a renda adquirir outros alimentos e alimentar o gado:

Eu gosto de fazer o queijo, isso faz parte de minha vida. Mas, as vezes os meninos querem comer e eu não posso dá, porque preciso vender para fazer a feira. Mas, quando o leite tá maior eu sempre faço um queijo para nós comer. (MC).

Minha filha às vezes a gente tem vontade de comer o queijo mas não pode, pois precisa vender o queijo. Aí às vezes eu tenho tanta vontade que tiro um pedacinho da beira do queijo e passo aliso o queijo para o meu marido não ver porque ele leva o queijo para vender na feira. Mas quando tem muito leite no inverno na fartura a gente come o queijo de manhã e meio dia se não tiver carne a gente come com feijão e farinha e aí tá alimentado, fica forte. (VS).

As camponesas enfatizam o enraizamento do produto no consumo diário e ao citar os momentos que não podem consumir aparentam uma tristeza momentânea, porém, em seguida falam da fartura com a chegada das chuvas. Elas ressaltam que vender o leite às indústrias implica em ficar sob o domínio de outros. Tais depoimentos nos mostram a relação da transmissão dos saberes e como esta produção está enraizada nas comunidades rurais. Como ressalta uma produtora: "Quando não faço queijo o dia não tem graça, parece que o dia não passa, é triste" (BC). A produtora reporta-se à temporalidade da atividade, com os seus antepassados, e a sua continuidade no presente que está relacionada a "uma herança cultural que permeia o território", resgatada pelas camponesas como alternativa para a sua sobrevivência. A continuidade dessa produção está intrinsecamente relacionada à cultura e à dimensão socioeconômica por meio das inter-relações das atividades leite-queijo e que proporcionam uma renda com a comercialização dos produtos.

O queijo de coalho é comercializado nas feiras semanais realizadas nas sedes dos citados municípios, quando as mulheres carregam a produção semanal, ou parte dessa, e entregam aos intermediários que, após fazerem a pesagem, pagam em espécie. Diferentemente do passado, o homem era o responsável pela comercialização, hoje, a mulher vende e, com a renda, compra os alimentos ou suprimentos para a sua família, fazem o pagamento das rações nos períodos secos e utilizam os recursos financeiros obtidos para suprirem outras necessidades. Durante a semana, os intermediários visitam os estabelecimentos rurais e adquirem o produto.

Ao estudar as relações de sociabilidade no Brasil, Sabourin (2006, p. 222) asseverou que as "feiras locais e os mercados de proximidade oferecem exemplos de produção e mobilização do laço social, de sociabilidade pelas relações diretas entre produtor- 
consumidor". Embora, não tenha estudado a comercialização de queijos da região sertaneja, a assertiva do autor foi verificada in loco. Constatamos que, entre as produtoras dos derivados e os comerciantes, não existe contrato firmado entre as partes, não há vínculo formal entre os membros, porém, assegura-se o compromisso entre os atores. Existe um compromisso informal combinado entre as partes, no qual o pagamento deverá ser realizado semanalmente em espécie às camponesas, essas relações estão baseadas no dinheiro líquido, indispensável para a reprodução social similares àquelas desenvolvidas no Circuito Inferior da Economia Ürbana ilustrado por Santos (2004). Como afirma uma das produtoras:

Nós vamos para a feira com o bolso vazio, não temos dinheiro, mas levamos os queijos produzidos durante a semana. Aí quando chegamos lá, pesamos o queijo e dizemos ao comerciante que já está a nossa espera, ele nem olha a gente pesando porque confia, depois é só pagar na hora. Com esse dinheiro fazemos a feira, pagamos a ração dos animais nesse período seco, e assim vamos vivendo (MIC).

De acordo com a produção média de queijo diário, realizamos uma conversão da renda obtida com essa produção, para entendermos o valor desse produto para a reprodução da família. Para tanto, inserimos dois valores do queijo tendo em vista essa variação existente, relacionada ao tipo de comércio.

\section{Tabela 01:. Produção e Renda do Queijo Caseiro em Monte Alegre de Sergipe, Nossa Senhora da Glória e Porto da Folha}

\begin{tabular}{|c|c|c|c|c|c|c|c|c|c|}
\hline \multirow{3}{*}{$\begin{array}{l}\text { Produção } \\
\text { Média de } \\
\text { leite/diária }^{8}\end{array}$} & \multirow{3}{*}{$\begin{array}{l}\text { Queijo de } \\
\text { Coalho } \\
\text { caseiro } \\
\text { Qtde } \\
\text { Dia/kg }\end{array}$} & \multirow{3}{*}{$\begin{array}{l}\text { Produção } \\
\text { de queijo } \\
\text { de coalho } \\
\text { Semanal } \\
\text { Qtde kg }\end{array}$} & \multirow{3}{*}{$\begin{array}{l}\text { Produção } \\
\text { de queijo } \\
\text { Anual } \\
\text { Qtde Kg }\end{array}$} & \multirow{2}{*}{\multicolumn{2}{|c|}{ Renda Semanal }} & \multirow{2}{*}{\multicolumn{2}{|c|}{ Renda mensal' $^{9}$}} & \multirow{2}{*}{\multicolumn{2}{|c|}{$\begin{array}{l}\text { Renda do queijo } \\
\text { Anual } 364 \text { dias }\end{array}$}} \\
\hline & & & & & & & & & \\
\hline & & & & 12,00 & 13,00 & 12,00 & 13,00 & 12,00 & 13,00 \\
\hline 50 litros & $5 \mathrm{~kg}$ & $35 \mathrm{~kg}$ & 1.820 & 420,00 & 455,00 & 1800,00 & $1.950,00$ & $21.840,00$ & $23.660,00$ \\
\hline
\end{tabular}

Fonte: Pesquisa de campo realizada em maio de 2016.

Na feira semanal, os queijos são pesados na caixa plástica e depois depositados em isopor e transportados para vários municípios.

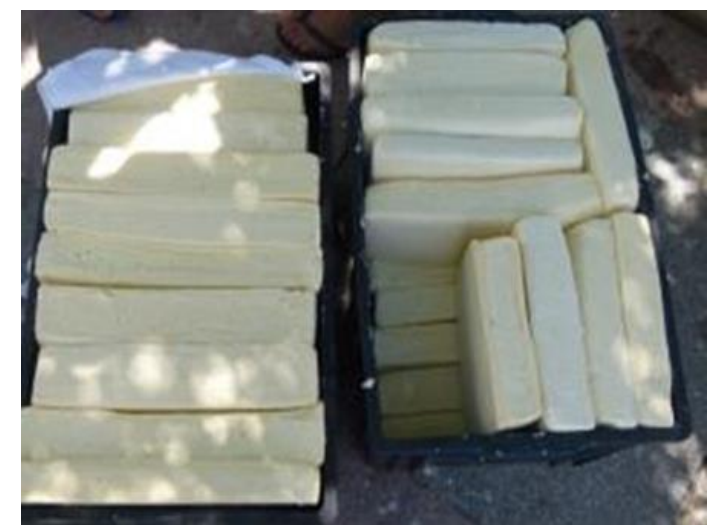

Figura 04 Feira-livre em Monte Alegre.

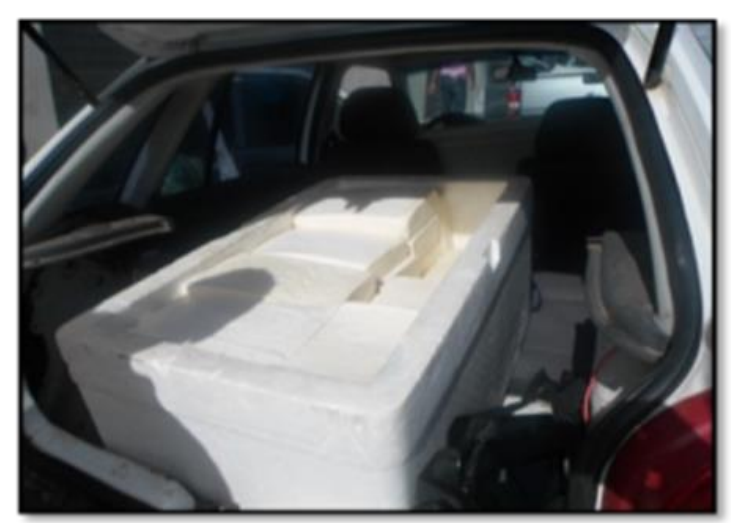

Fig. 05: transporte do Queijo de Coalho. 
Intrinsecamente ligada à produção de queijo de coalho aparece outra atividade - a suinocultura. Em todos os estabelecimentos rurais que produzem queijo de coalho existe um criatório de suínos, uma vez que o soro - resíduo proveniente da fabricação do queijo - é utilizado como alimentação para os suínos, fator por vezes determinante para a permanência da produção queijeira artesanal. Os animais são alimentados com o restolho da alimentação diária da família, milho, e, principalmente, com o soro. Os citados animais são comercializados nas feiras livres ou os intermediários visitam os estabelecimentos rurais e adquirem os produtos igualmente ao queijo sendo a transação comercial realizada em dinheiro vivo. Essa constitui uma segunda renda essencial na sustentabilidade do estabelecimento rural, ressaltado por Menezes (2009) como poupança sob o domínio feminino.
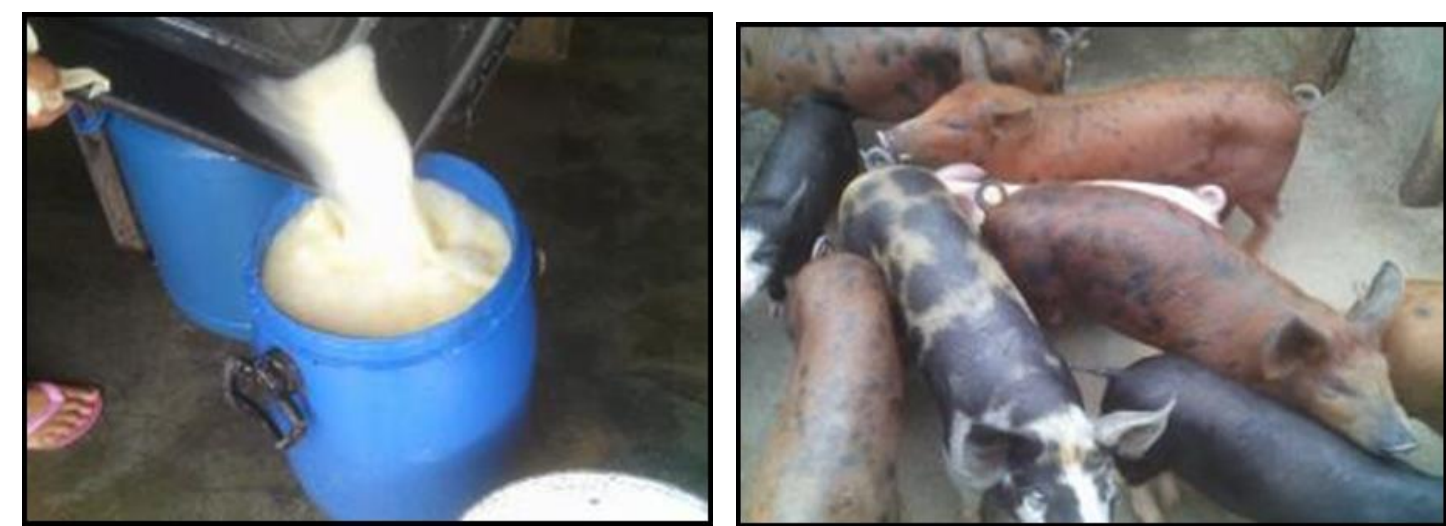

Fig. 06 - Resíduo da fabricação do queijo, o soro, Fig. 07 - Criação de Suínos, utilizado para a alimentação dos suínos.

A renda proveniente da comercialização desses animais é utilizada para a aquisição de vestimentas para os membros da família, pagamento de despesas domésticas e obtenção de novos suínos, e ficam quase sempre sobre o poder das mulheres, garantindo uma renda para estas camponesas e lhes possibilitando uma maior autonomia.

Fazendo o queijo eu tenho o porco, já que tenho o soro. Se não fosse o soro para criar o porco eu venderia o leite. O leite, o queijo e o porco estão unidos, todos são importantes para a nossa vida, pois quando um está mais fraco o outro ajuda. (MJ).

O cotidiano dessas mulheres é marcado pelo trabalho para o sustento da casa e o trabalho "da casa". Após a elaboração dos queijos, a mulher sertaneja dedica-se à organização do lar e, posteriormente, dedicará seu tempo ao preparo das refeições e do espaço do entorno da sua residência - o quintal. Esse território sob o seu domínio, ela utiliza para a plantação das ervas medicinais, árvores frutíferas, plantação de milho, feijão e verduras, assim como aproveita para inserir as pocilgas ou chiqueiros onde são criados os suínos. Após o almoço, é comum elas descansarem por uns trinta minutos, para revigorarem as suas energias, considerando que começam suas atividades às cinco horas da manhã. Depois reiniciam o ciclo, tendo em vista que, em alguns estabelecimentos rurais, a ordenha é realizada duas vezes por dia, o que denota a produção de queijos duas vezes, repetem-se, portanto, as atividades, inclusive com a alimentação dos suínos e a apartação do gado, ou seja, separação dos bezerros das vacas. 


\section{Considerações finais}

A produção do queijo de coalho caseiro nos municípios do território do Alto Sertão Sergipano apresenta-se como uma territorialidade criada com o intuito de continuar no território considerado como lugar de vida e de trabalho. Constatamos, com essa pesquisa, que a citada produção queijeira está interligada à identidade territorial das camponesas e seus familiares, cuja preservação do saber-fazer cultural protagonizado pelos antepassados dessas atoras sociais é algo inato às famílias.

Para além da relação cultural, essa atividade constitui a principal renda com a qual é mantida a soberania alimentar (garantia que os alimentos necessários para a sobrevivência sejam produzidos e/ou adquiridos pela família), uma vez que, a partir da comercialização do queijo obtêm-se os alimentos consumidos diariamente nos estabelecimentos rurais. Comprovamos as relações de proximidade entre as mulheres produtoras de queijo de coalho e a rede comercial, não sendo identificados conflitos entre os grupos, conformando uma relação onde impera a confiança tendo em vista que a produção semanal do queijo é adquirida no início da feira e o pagamento é realizado em espécie, sem contratos formais, constituindo uma característica do circuito inferior da economia discutido pelo professor Milton Santos (2004).

Verificamos que os estabelecimentos familiares não ultrapassam 100 hectares, o número de animais é reduzido e a mão de obra utilizada é estritamente familiar. Quanto ao sistema de produção, o queijo caseiro está sob o domínio das mulheres e observamos alterações relativas à maturação do queijo, ocorrendo essa mudança diante da demanda do mercado consumidor por produtos sem maturação, o denominado queijo branco, fato esse que ocorre em outras regiões queijeiras brasileiras como nos demais estados nordestinos e no estado de Minas Gerais. Além disso, observamos o predomínio do uso do coalho industrializado e um reduzido número de produtoras utilizando o coalho natural.

As camponesas produtoras do queijo de coalho, total 155 famílias nesse período (2011-2014), diante da seca que assolou o estado de Sergipe e o Alto Sertão Sergipano têm nessa atividade o sustentáculo do estabelecimento rural. É a partir da renda do queijo que são adquiridos os alimentos, o que conforma um recurso fundamental para a soberania alimentar da família. Embora a mulher seja a responsável pela produção, a renda é revertida para toda a família e, em alguns períodos do ano, é também utilizada para alimentar não somente os membros familiares, mas, os animais.

Com relação à suinocultura, verificamos a integração dessa atividade com a produção de queijo de coalho em todos os municípios e produtoras, essa é a segunda renda que em determinados momentos, sobretudo, no período das estiagens é essencial na sustentabilidade do sistema agroalimentar. Essa é a renda da mulher, mas, nos períodos críticos de seca essa renda é revertida para a aquisição de alimento para o rebanho, água e em serviços no estabelecimento rural.

As produtoras do queijo de coalho caseiro detêm aprendizados e técnicas de produção queijeira adquiridas e compartilhadas por gerações, embora aconteça um avanço na escolaridade nas jovens produtoras de queijo, o saber-fazer continua idêntico àquele transmitido pelas antepassadas. Ressaltamos que essa produção é assegurada pela demanda de um mercado consumidor que busca, no consumo desse alimento, uma aproximação do território e alimentos naturais, sem condimentos e aditivos químicos, enraizados na identidade. Esse alimento constitui parte de um modo de vida conforme uma cultura e tradição de comunidades rurais, e da população urbana que procura, no consumo desse alimento, alimentar o seu corpo e fortalecer sua identidade e, por fim, constitui em uma atividade autônoma sob a responsabilidade de mulheres que são guardiãs do queijo e da vida. 
O saber-fazer transmitido por essas sertanejas implica em uma forma de educação, no entendimento amplo do termo, bem como nos convida a pensar na formação e na divisão sexual do trabalho embutidas em tal relação, uma vez que se aprende por gerações os papéis e responsabilidade da mulher no seio da família e como passar os conhecimentos das técnicas da fabricação do queijo para manter suas famílias e seguir ativa nas relações de trabalho.

\section{Referências}

ALENCAR, José de. O Sertanejo. São Paulo: Cultrix, 1969.

ALVES, Ana Elizabeth Santos. Agroindústria Leite-laticínio, Trabalho e Qualificação: anotações introdutórias. IN: ALVES, Ana Elizabeth Santos; LIMA, Gilneide de Oliveira Padre; CAVALCANTI JR., Manoel Nunes. (Org.). Interfaces entre História, Trabalho e Educação. Campinas/SP: Alínea, 2009.p. 213-42.

ANDRADE, Manuel Correia de. Nordeste: alternativas da agricultura. Campinas, SP: Papirus, 1988.

ANDRADE, Manuel Correia de. A terra e o homem no Nordeste. 3. ed. São Paulo: Cortez, 1986.

BOURDIEU, Pierre. A dominação masculina. Trad. Maria Helena Kühner. Rio de Janeiro: Bertrand do Brasil, 1999.

CASCUDO, Luis da Câmara. História da alimentação no Brasil. 3. ed. São Paulo: Global, 2004.

CASTRO, Josué de. Geografia da fome. 11. ed. Rio de Janeiro: Civilização Brasileira, [1963] 2011.

CLAVAL, Paul. A Geografia Cultural: o estado da arte. In: ROSENDAHL, Zeny. CORREA. Roberto L. (Org.). Manifestações da cultura no espaço. Rio de Janeiro: EDUERJ, 1999, p. 59-97.

CONTI, José Bueno; FURLAN, Sueli Angelo. Geoecologia: o clima, os solos e a biota. In: ROSS, Jurandyr L. Sanches. Geografia do Brasil. São Paulo: EDUSP, 1996. p. 67-207.5. ed. rev. e ampliada. São Paulo: Editora da Universidade de São Paulo, 2008, p.67-208.

CRUZ, Fabiana Thomé da. Produtores, consumidores e valorização de produtos tradicionais: um estudo sobre qualidade de alimentos a partir do caso do Queijo Serrano dos Campos de Cima da Serra - RS. 2012. Tese (Doutorado em Desenvolvimento Rural) Programa de Pós-Graduação em Desenvolvimento Rural, Universidade Federal do Rio Grande do Sul, Porto Alegre, 2012.

DINIZ, José Alexandre Felizola. Geografia da agricultura. 2. ed. São Paulo: DIFEL, 1996.

GALINKIN, Ana Lúcia; BERTONI, Luci Mara. Gênero e educação: um caminho para a igualdade. In: BERTONI, Luci Mara; GALINKIN, Ana Lúcia. (Org.). Gênero e educação. Em Aberto, v. 27, n. 92, jul/dez. p. 21-42. Brasília: INEP, 2014. 
HIRATA, Helena; KERGOAT, Danièle. Novas configurações da divisão sexual do trabalho. Cadernos de Pesquisa, v. 37, n. 132, set./dez. 2007, p. 595-609.

INFOPÉDIA. Dicionário da Língua Portuguesa com Acordo Ortográfico. Porto: Porto, 2003-2016.

Disponível

em:

<http://www.infopedia.pt/dicionarios/linguaportuguesa/saberfazerfazer>. Acesso em: 12 fev. 2017.

KRONE, Evander Elói. Identidade e cultura nos campos de cima da serra (RS): práticas, saberes e modos de vida de pecuaristas familiares produtores do queijo serrano. 2009. 142f. Dissertação (Mestrado em Desenvolvimento Rural) - Programa de Pós-Graduação em Desenvolvimento Rural. Universidade Federal do Rio Grande do Sul, Porto Alegre, RS, 2009.

MENESES, José Newton C. Queijo artesanal de Minas: patrimônio cultural do Brasil. Dossiê interpretativo. v. 1. Belo Horizonte, 2006.

MENEZES, Sônia de Souza Mendonça. A força dos laços de proximidade na tradição e inovação no/do território sergipano das fabriquetas de queijo. 2009. 359f. Tese (Doutorado em Geografia) - Núcleo de Pós-Graduação em Geografia. Universidade Federal de Sergipe, São Cristóvão, SE, 2009.

MENEZES, Sônia de Souza Mendonça; LIBERATO, Rita Simone, CRUZ, Fabiana Thomé da. Guardiães do queijo coalho do sertão. Documentário. Aracaju - SE, 2014.

MINTZ. Sidney W. Comida e antropologia: uma breve revisão. Revista Brasileira de Ciências Sociais. vol.16 no. 47. São Paulo, Outubro 2001. p. 31-42.

PEREIRA. Mônica Cox de Britto. Revolução Verde. In: CALDART. Roseli Salete; PEREIRA. Isabel Brasil; ALENTEJANO, Paulo;FRIGORRO Gaudêncio. Dicionário da Educação do Campo. Rio de Janeiro, São Paulo: Escola Politécnica de Saúde Joaquim Venâncio, Expressão Popular, 2012, págs: 685-691.

SABER-fazer. In: INFOPÉDIA. Dicionário da Língua Portuguesa com Acordo Ortográfico. Porto: Porto Editora, 2003-2016. Disponível em: <http://www.infopedia.pt/dicionarios/linguaportuguesa/ saber-fazer>. Acesso em: $12 \mathrm{fev}$. 2017.

SABOURIN, Eric. Práticas sociais, políticas públicas e valores humanos. In: SCHNEIDER, Sérgio (Org.). A diversidade da agricultura familiar. Porto Alegre: EdUFRGS, 2006. p. 21539.

SANTOS, Milton. $O$ espaço dividido: os dois circuitos da economia urbana dos países subdesenvolvidos. $2^{\mathrm{a}}$ ed. São Paulo: EDUSP, 2004.

SAVIANI, D. Trabalho e Educação: Fundamentos Históricos e Ontológicos. Revista Brasileira de Educação, v. 12, n. 34, jan./abr. 2007. p.152-65. Disponível em: <http://www.scielo.br/pdf/rbedu/v12n34/a12v1234.pdf>. Acesso em: 11 fev. 2017.

WOORTMANN, Ellen F. Herdeiros, parentes e compadres. São Paulo: Hucitec; Brasília: EDUNB, 1995. 
WOORTMANN, Ellen F.; WOORTMANN, Klaas. O trabalho da terra: a lógica e a simbólica da lavoura camponesa. Brasília: EDUNB, 1997.

\footnotetext{
${ }^{1}$ Professora Titular do Departamento de Filosofia e Ciências Humanas da Universidade Estadual do Sudoeste da Bahia - UESB. Docente do Programa de Pós-Graduação em Memória: Linguagem e Sociedade (PPGMLS/UESB). Vice-coordenadora do Museu Pedagógico/UESB. Coordenadora do GePAD - Grupo de Estudos e Pesquisas sobre Gênero, Política, Álcool e Drogas (MP/UESB).

${ }^{2}$ Professora Adjunta do Departamento de Geografia da Universidade Federal de Sergipe - UFS. Docente do Programa de Pós-Graduação em Geografia - PPGEO/UFS. Coordenadora do Laboratório de Formação Profissional em Geografia. Líder do Grupo de Estudos e Pesquisas sobre Alimentos e Manifestações Tradicionais CNPq/UFS.
}

${ }^{3}$ Embora na língua portuguesa, o feminino de ator corresponda à palavra atriz, optamos por uma linguagem feminista porque o referido termo não contempla nosso objetivo.

${ }^{4}$ Revolução Verde: após a década de 1950 foi divulgada e colocada em prática nos países com potencial agrícola esse pacote tecnológico fundamentado na quimificação e na mecanização do campo, além da inserção de sementes elaboradas em laboratórios difundidas com o objetivo de aumentar a produtividade nos grandes estabelecimentos rurais, abalizado na ideia do progresso e da redução da fome (PEREIRA, 2012).

${ }^{5}$ Saber-fazer: termo francês savoir-faire, é um conjunto de conhecimentos, aptidões e técnicas adquiridas com a experiência (INFOPEDIA, 2017).

${ }^{6}$ Tais relatos foram analisados a partir do Documentário "Guardiães do queijo coalho do sertão" (MENEZES, 2014).

${ }^{7}$ Optamos em inserir as iniciais dos entrevistados, para deixar as entrevistadas no anonimato. Em 2016 entrevistamos 10 produtoras de queijo nos municípios de Nossa Senhora da Glória, Monte Alegre de Sergipe e Porto da Folha.

${ }^{8}$ A produção mensal com base em trinta dias e a produção anual em 364 dias uma vez que existe um único dia no decorrer do ano no qual não se produz queijo: a sexta-feira da paixão.

${ }^{9}$ Essa tabela apresenta uma média de queijos produzidos por dia, no período da seca. Exemplos estes apresentados referem-se ao período de seca $=$ verão, no período $=$ chuvoso quando se eleva a produção do leite bem como o rendimento do leite, aumenta a produção de queijo, logo, esse valor é alterado positivamente.

Recebido: Fevereiro/2017.

Aprovado: Abril/2017. 